\title{
A liberalização comercial e o grau de abertura da economia brasileira*
}

\section{Trade liberalization and openness of the Brazilian economy}

Fernando Antônio Ribeiro Soares ${ }^{1}$ André Nunes ${ }^{2}$
Recebido em 15/12/2011 Aprovado em 25/04/2012.

1 Doutor em Economia (UnB) e Assessor da Secretaria Executiva do Ministério da Fazenda.

2 Doutor em Economia (UnB) e Professor do UniCEUB.

\section{Resumo}

$\mathrm{O}$ artigo trata das mudanças ocorridas na economia brasileira decorrentes da liberalização comercial dos anos 1990. Em especial, é discutida a alteração do grau de abertura no país. Para tanto, utiliza-se o coeficiente de abertura tradicional para o setor industrial, proposto por Haguenauer, Markwald e Pourchet (1998). São também construídas outras duas medidas: (i) o coeficiente agregado de abertura; e (ii) os coeficientes de abertura para os setores industrial (outra versão) e agropecuário. Os resultados obtidos indicam uma ampliação dos fluxos comerciais no que se refere às importações, sem, contudo, apresentar a elevação correspondente pelo lado das exportações, excetuando-se no que se refere às exportações provenientes do setor agropecuário. Desse modo, evidencia-se que as variações ocorridas nos coeficientes de abertura, além do efeito da abertura comercial, também foram fortemente afetadas pelo comportamento da taxa de câmbio.

Palavras-chave: Liberalização comercial. Abertura econômica. Medidas de abertura. Coeficientes e abertura.

\begin{abstract}
This paper deals with changes in the Brazilian economy that occurred since the 1990s trade liberalization. In particular, we discuss the change in the degree of openness in the country. For that, we use the traditional coefficient of openness to the industrial sector proposed by Haguenauer, Markwald and Pourchet (1998). Furthermore we also build up two other measures: (i) the aggregate coefficient of openness; and ( ii) the coefficients of openness to the industrial (another version) and agriculture sectors. The results obtained in the three opening measures indicate an expansion of trade flows with regard to imports, but without presenting the corresponding elevation on the export side, except with regard to exports from the agricultural sector. Thus, it is evident that the variations in the coefficients of openness, beyond the effect of trade liberalization, were also strongly affected by the behavior of the exchange rate.
\end{abstract}

Keywords: Trade liberalization. Economic openness. Measures of openness. Openness coefficients. 


\section{Introdução}

A estrutura da proteção comercial vigente na economia brasileira a partir da década de 1930, quando passou a ser adotado o modelo de desenvolvimento de industrialização via substituição de importações, surgiu, primeiramente, como uma maneira de mitigar os desequilíbrios do balanço de pagamentos e, posteriormente, como o próprio nome do modelo diz, com o objetivo de promover a industrialização do país. A opção protecionista efetivamente propiciou o nascimento de uma indústria nacional, mas também incentivou o crescimento de uma indústria altamente concentrada e, em muitos casos, ineficiente. Com isso, as políticas comerciais oriundas do processo de substituição de importações geraram importantes distorções. Entre elas, podem-se citar: (i) a redistribuição inadequada de recursos dos setores exportadores e, principalmente, dos consumidores para os setores competidores de importações; (ii) as falhas de competição; ${ }^{3}$ (iii) a ineficiência devido à escala insuficiente de produção; e (iv) a alocação ineficiente de recursos.

Visando reverter esse quadro, ao final dos anos oitenta e no começo dos anos noventa, teve início uma reforma comercial no Brasil. Seu objetivo central era o desmantelamento da estrutura de proteção até então vigente no país. A liberalização comercial, apesar da existência de falhas de implementação, propiciou a alteração na estrutura da economia brasileira e possibilitou que ocorressem importantes melhorias na alocação de recursos, crescimento da eficiência produtiva e ganhos de bem-estar. Tais melhorias necessariamente decorrem - mesmo que não exclusivamente - do maior grau de exposição do país aos mercados externos. Isso, por sua vez, pode ser mensurado pelos coeficientes de abertura da economia, em especial pelo coeficiente de importações. Um processo de liberalização comercial deve, portanto, resultar em maiores coeficientes de importação, mas também de exportação, sendo esta a proposta de análise central deste artigo.

$\mathrm{O}$ artigo apresenta as alterações ocorridas no grau de exposição da economia brasileira, a partir da reforma, utilizando-se dos coeficientes tradicionais de abertura comercial para o setor industrial, sendo estes propostos por Haguenauer, Markwald e Pourchet (1998). Além dos co- eficientes tradicionais, construíram-se outras duas medidas: os coeficientes agregados de abertura e os coeficientes de abertura para os setores industrial e agropecuário. Apesar de limitações metodológicas, todos os coeficientes apresentaram tendência de aumento das importações, como decorreria de uma abertura comercial; porém, pelo lado das vendas externas, diferentemente do que se esperaria, houve estagnação ou mesmo declínio dos coeficientes de exportação.

Feitas essas considerações iniciais, segue a estrutura do artigo. O trabalho está estruturado em cinco seções, sendo a primeira, esta introdução. Na segunda seção, são apresentadas as medidas de abertura de Haguenauer, Markwald e Pourchet (1998), além de ser feita a análise dos coeficientes de abertura total da indústria para o período de 1985 a 1998. Na terceira seção, apresentam-se os coeficientes agregados de abertura que buscam determinar o grau de inter-relacionamento da economia brasileira como um todo com o resto do mundo. Eles são obtidos a partir das exportações e das importações como proporções do produto interno bruto. Na quarta seção, são destacados os coeficientes de abertura construídos para os setores industrial e agropecuário. Por fim, a última seção é dedicada às considerações finais.

\section{Coeficientes de abertura de Haguenauer, Ma- rkwald e Pourchet ${ }^{4}$}

Os coeficientes de exportação e de importação podem ser definidos, respectivamente, como a razão das exportações e das importações sobre o valor da produção doméstica do mesmo bem.

$$
\begin{aligned}
& C X=\frac{X}{V P} \\
& C M=\frac{M}{V P}
\end{aligned}
$$

Onde: $C X$ é o coeficiente de exportações; $X$ é o valor das exportações; $V P$ é o valor da produção doméstica; $M$ é o valor das importações e $C M$ é o coeficiente de importação.

\footnotetext{
${ }^{4}$ Outras estimativas do grau de abertura da economia brasileira podem ser vistas em Bonelli (1997), Moreira e Correa (1997), Fonseca, Carvalho Jr. e Pourchet (2000). 
Outra maneira de medir o grau de abertura de uma economia é o coeficiente de penetração de importações. Ele é definido como a razão entre as importações e o consumo aparente (ou demanda doméstica), onde o consumo aparente se refere ao valor da produção somado às importações líquidas. $\mathrm{O}$ coeficiente de penetração de importações pode ser assim definido:

$$
C P M=\frac{M}{V P+(M-X)}
$$

Onde: $C P M$ é o coeficiente de penetração de importações; $M$ é o valor das importações; $V P$ é o valor da produção; $(M-X)$ são as importações líquidas e $V P+(M-$ $X)$ é o consumo aparente.

O coeficiente de penetração de importação nos diz qual percentagem da demanda doméstica é suprida por produtos provenientes de importações. Temos então que os coeficientes de exportação e de importação, bem como o de penetração de importações, são indicadores do volume de comércio exterior de um país, determinando o seu grau de abertura.

As medidas usuais de coeficientes de abertura foram elaboradas por Haguenauer, Markwald e Pourchet (1998). Eles construíram os coeficientes de exportação e de importação para o Brasil, cobrindo o período de 1985 a 1998. A medida foi limitada à análise dos coeficientes relativos aos setores da indústria de transformação e da indústria extrativa mineral.

$\mathrm{Na}$ elaboração dos coeficientes de abertura para o setor industrial, Haguenauer, Markwald e Pourchet (1998) utilizaram os dados de importações e de exportações trabalhados pela Fundação Centro de Estudos do Comércio Exterior (Funcex), que, por sua vez, foram primariamente elaboradoras pela Secretaria de Comércio Exterior do Ministério do Desenvolvimento, Indústria e Comércio Exterior (SECEX/MDIC). A série referente ao valor da produção industrial foi construída a partir de dados do Instituto Brasileiro de Geografia e Estatística (IBGE). Essa série, valorada em moeda nacional, foi construída com base em índices de produção física industrial e de preços. Em seguida, essa série foi transformada em dólares dos Estados Unidos da América (EUA) pela taxa de câmbio média mensal de venda, que, a partir desse resultado, foi anualizada. Assim, utilizando-se dos referidos dados, foram calculadas as séries dos coeficientes de exportação e importação.

Na Tabela 1, são apresentados os coeficientes de exportação e importação para o total da indústria (indústria de transformação e extrativa mineral).

Tabela 1-Coeficientes de abertura, total da indústria, período de 1985 a $1998(\%)$

\begin{tabular}{c|c|c}
\hline Ano & $\begin{array}{c}\text { Coeficientes de } \\
\text { Exportação }\end{array}$ & $\begin{array}{c}\text { Coeficientes de } \\
\text { Importação }\end{array}$ \\
\hline 1985 & 13,2 & 7,1 \\
1986 & 10,7 & 6,7 \\
1987 & 11,4 & 6,8 \\
1988 & 12,5 & 5,5 \\
1989 & 10,0 & 5,5 \\
1990 & 7,9 & 5,4 \\
1991 & 10,8 & 7,3 \\
1992 & 12,2 & 7,1 \\
1993 & 11,3 & 7,6 \\
1994 & 10,7 & 8,3 \\
1995 & 9,9 & 10,8 \\
1996 & 10,3 & 11,5 \\
$1997^{\mathrm{a}}$ & 11,0 & 12,8 \\
$1998^{\mathrm{b}}$ & 11,6 & 13,4 \\
\hline
\end{tabular}

Fonte: HAGUENAUER, Lia; MARKWALD, Ricardo A.; POURCHET, Henry. 1998. Estimativas do valor da produção industrial e a elaboração de coeficientes de exportação e importação da indústria brasileira (198596). Texto para Discussão no 563. Brasília: IPEA para os anos entre 1985 e 1996. Os anos restantes - 1997 e 1998 - foram atualizados de acordo com dados fornecidos pelos autores ${ }^{5}$.

Analisando os dados dispostos na tabela anteriormente apresentada, verifica-se que, inclusive após a liberalização comercial, ao contrário do que se poderia esperar, os coeficientes de exportação para o total da indústria apresentaram-se estáveis ou mesmo cadentes. Os coeficientes de importação, por outro lado, mostram uma substancial ampliação após a reforma comercial, o que vem a demonstrar o alargamento do grau de abertura da economia brasileira. Deve-se considerar que o coeficiente de importação, devido ao exacerbado viés anti-importador característico da antiga política comercial

\footnotetext{
5 Notas a, b: para os anos de 1997 e 1998 foram utilizados os coeficientes de penetração de importações.
} 
brasileira, teve seus valores substancialmente alterados com a reforma.

Os coeficientes de exportação apresentaram um comportamento oscilante quando se observa toda a série. Quando se enfocam os anos posteriores ao início da reforma, observa-se um comportamento de relativa estabilidade. Ocorreu uma ligeira expansão em 1992 em relação a 1991 - início da reforma - e ligeira queda de 1993 em relação a 1992. Quando se analisam os dois anos posteriores a 1993, no entanto, percebe-se uma queda nos coeficientes de exportação, como pode ser visto na Tabela 1. Nos três últimos anos da série (1996, 1997 e 1998), observa-se uma tendência de ligeira recuperação dos coeficientes.

Gráfico 1 - Coeficiente de abertura total da indústria

\section{Gráfico 1 - Coeficientes de Abertura Total da Indústria (1985/1996)}

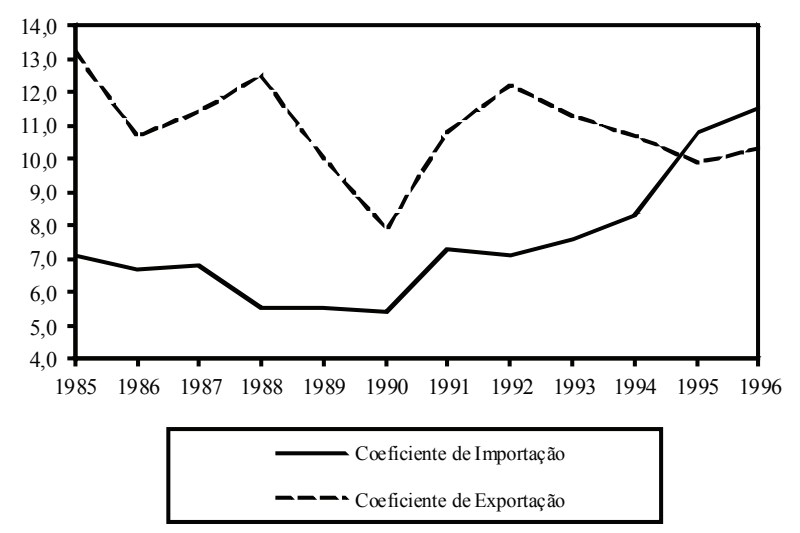

Fonte: Elaboração dos autores

Com a reforma comercial, era de se esperar uma tendência ascendente dos coeficientes de exportações. Isso, no entanto, não se verificou. Esse comportamento diferente do esperado pode ser atribuído a dois fatores: (i) o aumento do valor da produção medido em dólares decorrente da valorização cambial, proposição destacada por Haguenauer, Markwald e Pourchet (1998); ${ }^{6}$ e (ii) os impactos negativos sobre exportações brasileiras também devido à valorização cambial.
O aumento do valor da produção medido em dólares correntes, que se encontra no denominador da medida de abertura, impacta negativamente o coeficiente de exportação. Dessa forma, a valorização da taxa de câmbio, principalmente aquela ocorrida após o anúncio do Plano Real, tendeu a aumentar o valor da produção medido em dólares, o que, consequentemente, diminuiu o coeficiente de exportação. Portanto, há uma variação espúria na medida representada por esse coeficiente. ${ }^{7} \mathrm{O}$ segundo elemento, que também contribuiu no sentido de diminuir os coeficientes de exportação, é estreitamente relacionado a um evento econômico associado a variações na taxa de câmbio. O aumento do preço dos bens exportáveis decorrente da valorização cambial desestimulou as vendas externas e desacelerou a taxa de crescimento das exportações brasileiras.

Ainda em relação à desaceleração do ritmo das vendas externas, pode-se constatar que nos três primeiros anos do Plano Real - 1994, 1995 e 1996 -, a taxa de crescimento das exportações, considerando o ano anterior, foi de, respectivamente, $12,94 \% ; 6,80 \%$ e $2,67 \%$. Ratifica-se, dessa forma, a estagnação dos coeficientes de exportações, o que, por outro lado, contraria as expectativas de que a reforma abriria comercialmente a economia brasileira.

$\mathrm{Na}$ outra ponta, analisando pelo lado das importações, percebe-se que a reforma comercial mostrou-se eficiente para abrir a economia brasileira aos fluxos comerciais, dado que os coeficientes de importação apresentaram tendência de crescimento a partir de 1991. Deve-se salientar que a análise dos coeficientes de importação apresenta o mesmo problema visto no coeficiente de exportação no que tange ao valor da produção. Como a taxa de câmbio apresentou-se valorizada a partir de 1994, ter-se-ia um maior valor da produção industrial, o que, de acordo com a forma cálculo, causaria uma diminuição do coeficiente de importação. Outro fator que contribuiria, pelo menos no início da década de noventa - entre 1990 e 1992 - para a redução dos coeficientes de importação seria a desaceleração da atividade econômica. A queda no nível de atividade implicaria redução da absorção e, por conseguinte, diminuiria o consumo privado, o consumo

\footnotetext{
7 Ter-se-iam, portanto, problemas de mensurabilidade e não

necessariamente econômicos.
}

\footnotetext{
6 A respeito da valorização da taxa de câmbio real na segunda metade da década de 1990, ver Soares e Paula Pinto (2008) e Soares e Nunes (2010).
} 
do governo e os investimentos. Logo, haveria outra razão para a redução dos coeficientes de importação.

Esses argumentos sinalizam para um não aumento dos coeficientes de importação industrial, fato que contrariaria a proposição de abertura da economia aos fluxos de comércio. Porém, apesar de tais impedimentos, ao analisar a série dos coeficientes de importação (Gráfico 1), percebe-se um comportamento de contínua ascendência deles a partir da reforma comercial, o que confirma a tese de ampliação do grau de abertura da economia.

\section{Coeficientes agregados de abertura}

Os coeficientes agregados de abertura também buscam determinar o grau de inter-relacionamento da economia com o resto do mundo. São obtidos por meio das exportações e importações como proporções do produto interno bruto. Podem ser assim definidos:

$$
\begin{aligned}
& C X A=\frac{X}{P I B} \\
& C M A=\frac{M}{P I B}
\end{aligned}
$$

Onde: CXA e CMA são, respectivamente, os coeficientes de exportação e de importação agregados; $X$ é o valor das exportações; $M$ é o valor das importações e $P I B$ é o produto interno bruto.

Os coeficientes agregados de abertura, quando comparados com os coeficientes vistos na seção anterior, podem ser considerados medidas mais genéricas devido à ponderação das exportações e das importações pelo produto total da economia ao invés do valor da produção setorial. Dessa forma, apresentam a vantagem de demonstrar a tendência global do grau de abertura. Porém, pecam pela excessiva amplitude, não permitindo descrever detalhadamente quais setores se tornaram mais integrados à economia mundial. Seus dados estão dispostos na Tabela 2.

\begin{tabular}{|c|c|c|c|c|c|}
\hline Ano & Exportações (R\$) & $\begin{array}{c}\text { Importações } \\
(R \$)\end{array}$ & $\begin{array}{l}\text { PIB } \\
(\mathrm{R} \$)\end{array}$ & $\begin{array}{c}\text { Coeficientes de } \\
\text { exportação } \\
(\%)\end{array}$ & $\begin{array}{c}\text { Coeficientes de } \\
\text { importação } \\
(\%)\end{array}$ \\
\hline 1985 & 57,6 & 29,6 & 504 & 11,44 & 5,88 \\
\hline 1986 & 110,8 & 69,6 & 1.336 & 8,30 & 5,21 \\
\hline 1987 & 373,7 & 214,6 & 4.209 & 8,88 & 5,10 \\
\hline 1988 & $3.217,5$ & $1.391,4$ & 31.491 & 10,22 & 4,42 \\
\hline 1989 & $35.406,2$ & $18.810,8$ & 400.000 & 8,85 & 4,70 \\
\hline 1990 & $780.174,7$ & $513.219,2$ & 11.000 .000 & 7,09 & 4,67 \\
\hline 1991 & $4.675 .185,3$ & $3.111 .122,2$ & 57.400 .000 & 8,14 & 5,42 \\
\hline 1992 & $58.739 .534,3$ & $33.730 .963,8$ & 619.500 .000 & 9,48 & 5,44 \\
\hline 1993 & 1.268 .160 .000 & 809.632 .000 & 14.116 .000 .000 & 8,98 & 5,74 \\
\hline 1994 & 28.225 .280 .000 & 21.274 .240 .000 & 422.965 .838 .850 & 6,67 & 5,03 \\
\hline 1995 & 42.677 .161 .020 & 45.574 .245 .210 & 658.141 .000 .000 & 6,48 & 6,92 \\
\hline 1996 & 48.224 .470 .000 & 53.834 .010 .000 & 778.820 .353 .000 & 6,19 & 6,91 \\
\hline 1997 & 57.229 .200 .000 & 66.254 .760 .000 & 866.722.721.379 & 6,60 & 7,64 \\
\hline
\end{tabular}

Tabela 2: Coeficientes agregados de abertura (1985-1997)

Fonte: Elaborada pelos autores a partir de dados do Banco Central do Brasil/Departamento Econômico, obtidos em: i) MELO, Fabiana Xavier Dezouzart Drummond de. A taxa virtual: uma alternativa para a taxa de câmbio de equilíbrio. Brasília, 1998. (Mestrado em Economia) - Universidade de Brasília, Brasília, 1998; ii) dados obtidos junto ao Departamento Econômico do Banco Central do Brasil em novembro de 1998 e Secretaria de Comércio Exterior, 1998. Balança comercial brasileira (janeiro/dezembro - 1998). Brasília: Ministério do Desenvolvimento, Indústria e Comércio.

Conforme os dados da Tabela 2, observa-se que o coeficiente agregado de exportação para os anos que se estendem de 1985 a 1997 apresentou tendência eminentemente declinante. A explicação desse comportamento correlaciona-se àquela aplicada para os coeficientes de exportação para o setor industrial de Haguenauer, Markwald e Pourchet (1998). Assim, além dos problemas de mensurabilidade do coeficiente, há novamente a questão da valorização cambial ocorrida durante a década de noventa, proveniente do Plano Real. 
Gráfico 2 - Coeficientes Amplos de abertura 1985/1997

Gráfico 2

Coeficientes Amplos de Abertura - 1985/1997
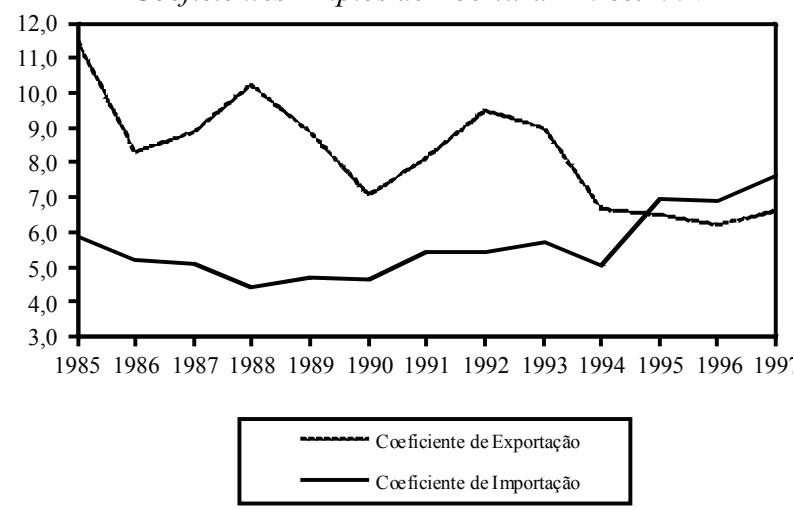

Fonte: Elaboração dos autores

Outra possível explicação para o declínio desses coeficientes encontra-se na reorientação da política cambial brasileira. No início da década de oitenta, em decorrência da crise da dívida, foi necessária a geração de vultosos superávits comerciais. Como resultado, devido às constantes desvalorizações cambiais, o volume exportado aumentou e, consequentemente, os coeficientes de exportação. Na segunda metade da década de 1980 e ao longo da década de 1990, a política econômica não estava mais voltada para a superação dos desequilíbrios externos, mas sim dos desequilíbrios internos. Especificamente, buscava-se o controle do processo inflacionário. Dessa forma, houve reorientação da política cambial, que priorizou o combate ao aumento de preços. Para tanto, era necessária uma taxa de câmbio valorizada de forma a constituir uma âncora cambial. ${ }^{8},{ }^{9}$ Consequentemente, os coeficientes de exportação foram condicionados aos novos objetivos da política governamental.

Os coeficientes de importação, por outro lado, apresentaram um comportamento oposto aos de exportação, conforme pode ser visto no Gráfico 2. Observa-se uma tendência crescente ao longo da série, sendo tal ten-

8 A âncora cambial atua no combate à inflação de três formas: (i) reversão das expectativas inflacionárias; (ii) combate à indexação; e (iii) aumento da oferta de mercadorias importadas e, consequentemente, aumento da competição nos setor produtores de bens e serviços comercializáveis. A esse respeito, ver: Dornbusch (1986); Bruno (1991); Calvo e Végh (1993); Rebelo e Végh (1995); Edwards (1996); Calvo e Végh (1998).

9 A construção da âncora cambial durante o Plano Real pode ser vista em Soares (2010). dência, ou sua inclinação no gráfico, acentuada a partir da reforma iniciada em 1991. Assim, confirma-se o aumento do grau de abertura da economia brasileira em decorrência da reforma comercial. Deve-se, entretanto, considerar que os efeitos da reforma, a partir do Plano Real, foram ampliados pela âncora cambial. Logo, possibilitou-se um incremento ainda maior das importações.

\section{Coeficientes de abertura para os setores in- dustrial e agropecuário}

Os coeficientes de abertura para o setor industrial e agropecuário a serem construídos nesta seção são analiticamente mais vantajosos que os coeficientes de Haguenauer, Markwald e Pourchet (1998) e que os coeficientes agregados de abertura. Os coeficientes de abertura para o setor industrial tornam-se limitados ao omitirem o setor agropecuário, um dos setores mais influenciados pela liberalização comercial por estar associado às vantagens comparativas nacionais. Os coeficientes agregados de abertura, por sua vez, pecam pela generalidade. A produção de um coeficiente menos genérico, mas que englobe os setores industrial e agropecuário, possibilita uma medida mais acurada do inter-relacionamento comercial entre os países.

O coeficiente de exportação industrial-agropecuário $\left(C X_{I A}\right)$ é a razão entre as exportações de ambos os setores e o valor da produção também de ambos os setores:

$$
C X_{I A}=\frac{X_{I A}}{V P_{I A}}
$$

Onde: $X_{I A}=X_{I}+X_{A}$ é o somatório das exportações industriais e agropecuárias, e $V P_{I A}=V P_{I}+V P_{A}$ é o somatório dos valores da produção industrial e agropecuária.

Analogamente, o coeficiente de importação industrial-agropecuário $\left(C M_{I A}\right)$ pode ser definido como a divisão das importações industriais mais as importações do setor agropecuário pelo somatório dos valores da produção de ambos os setores:

$$
C M_{I A}=\frac{M_{I A}}{V P_{I A}}
$$


Onde: $M_{I A}=M_{I}+M_{A}$ é o somatório das importações industriais e agropecuárias.
A Tabela 3 apresenta as séries de coeficientes de abertura para os setores industrial e agropecuário entre os anos 1990 e 1997.

Tabela 3 - Coeficientes de abertura, setores industrial e agropecuário (1990-1997)

\begin{tabular}{|c|c|c|c|c|c|}
\hline Ano & $\begin{array}{l}\text { Exportações (1.000 } \\
\text { - moeda corrente) }\end{array}$ & $\begin{array}{l}\text { Importações (1.000 } \\
\text { - moeda corrente) }\end{array}$ & $\begin{array}{c}\text { Valor da Produção } \\
\text { (1.000 - moeda } \\
\text { corrente) }\end{array}$ & $\begin{array}{l}\text { X/VP } \\
(\%)\end{array}$ & $\begin{array}{c}\text { M/VP } \\
(\%)\end{array}$ \\
\hline 1990 & 2.138 .036 .840 & 1.406 .187 .660 & 27.966 .915 .000 & 7,64 & 5,03 \\
\hline 1991 & 12.940 .485 .000 & 8.598 .825 .470 & 136.284 .264 .000 & 9,50 & 6,31 \\
\hline 1992 & 162.906 .828 .480 & 93.520 .700 & 1.505 .393 .212 .000 & 10,82 & 6,21 \\
\hline 1993 & 3.478 .817 .650 & 2.278 .848 .880 & 33.522 .725 .000 & 10,38 & 6,80 \\
\hline 1994 & 28.304 .250 & 21.170 .560 & 295.321 .132 & 9,58 & 7,17 \\
\hline 1995 & 42.785 .520 & 45.974 .240 & 489.166 .156 & 8,75 & 9,40 \\
\hline 1996 & 48.224 .470 & 53.301 .000 & 554.754 .156 & 8,69 & 9,61 \\
\hline 1997 & 57.229 .200 & 66.254 .760 & 610.555 .588 & 9,37 & 10,85 \\
\hline
\end{tabular}

Fonte: Elaborada pelos autores a partir de dados obtidos junto ao Departamento Econômico do Banco Central do Brasil em novembro de 1998; junto ao Departamento de Contas Nacionais da Diretoria de Pesquisa do Instituto Brasileiro de Geografia e Estatística em junho de 1999; e Secretaria de Comércio Exterior. 1998. Balança comercial brasileira (janeiro/dezembro - 1998). Brasília: Ministério do Desenvolvimento, Indústria e Comércio ${ }^{10}$.

Diferentemente dos outros dois coeficientes de exportação abordados, o industrial e o agregado, o coeficiente de exportação para os setores industrial e agropecuário apresentou maiores taxas a partir de 1991, quando comparado com o período pré-reforma, fato esse que reflete crescimento das exportações. Dessa maneira, acredita-se que houve a intensificação dos fluxos comerciais brasileiros a partir liberalização comercial. Comparando o coeficiente de exportação para o ano de 1990 com a média dos coeficientes de exportação para os demais anos da série (1991 a 1997), obtém-se um crescimento de 25,39\% no coeficiente após o início da reforma comercial. Comparando esse resultado, particularmente com o apresentado por Haguenauer, Markwald e Pourchet (1998), pode-se afirmar que a diferença está fundamentalmente associada ao desempenho exportador do setor agropecuário. Logo, pode-se concluir que esse setor foi mais eficiente em se reestruturar no ambiente pró-competitivo que surgiu após a reforma comercial.

\footnotetext{
${ }^{10}$ As exportações e importações foram convertidas em moeda nacional corrente pela taxa de câmbio nominal dada pelo valor médio anual de venda. As exportações, importações e o valor da produção em moeda corrente doméstica apresentam a seguinte ordenação: de 1990 a 1992 valores em cruzeiros, 1993 em cruzeiros reais e de 1994 a 1997 em reais.
}

Gráfico 3 - Coeficientes de Abertura dos Setores Industrial e Agropecuário 1990/1997

Gráfico 3 - Coeficientes de Abertura dos Setores Industrial e Agropecuário (1990/1997)

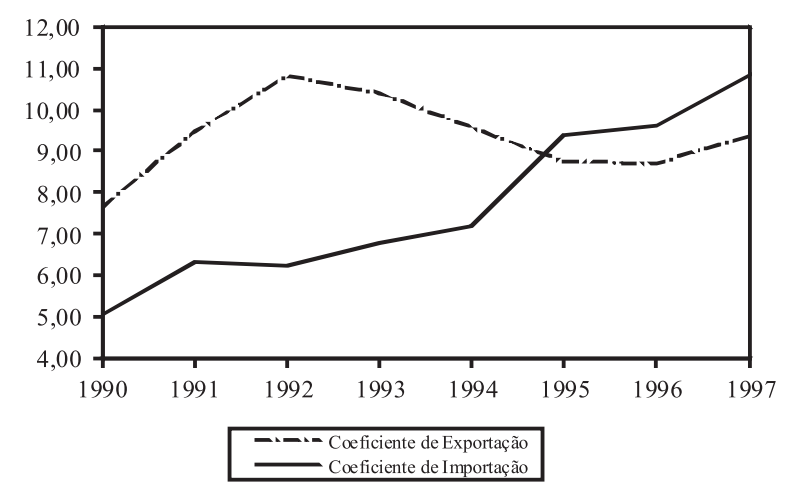

Fonte: Elaboração dos autores.

Utilizando a média dos coeficientes de importação relativos aos três anos de implementação da reforma (1991, 1992 e 1993), no valor de 6,44\%, para confrontá-la com o coeficiente de 1990, no valor de 5,03\%, temos um crescimento de aproximadamente $28 \%$. Em outro exercício, comparando o ano de 1994, quando ocorreram reduções adicionais nas tarifas de importação e a taxa de câmbio iniciou seu processo de valorização, com o de 1990, percebe-se um crescimento de $42,54 \%$ no coeficiente de importação. 
Nos demais anos da série - 1995, 1996 e 1997-o coeficiente de importação demonstrou comportamento de contínua elevação (Gráfico 3), com taxas de crescimento com relação a 1990 de, respectivamente, 46,49; 91,05 e $115,71 \%$. Poder-se-ia dizer que a expansão das importações nesses três anos seria uma resultante do contínuo processo de valorização cambial. Entretanto, a média dos índices da taxa de câmbio real efetiva para esses anos, calculada segundo o IPA-DI, não demonstrou significativas alterações, enquanto os coeficientes de importação continuaram a se elevar. ${ }^{11}$ Tal resultado nos leva a considerar que o crescimento das importações não foi afetado apenas pela política cambial. Reforça-se, dessa forma, a proposição de a reforma comercial ter ampliado o grau de abertura da economia brasileira.

\section{Considerações finais}

As medidas de abertura encontradas na literatura econômica apresentam diversos problemas de mensurabilidade ligados à determinação dos valores das importações, das exportações e, principalmente, dos valores da produção, que são artificialmente alterados por variações nas taxas de câmbio, propiciando, consequentemente, variações indesejadas nos coeficientes de importação e de exportação. Da mesma forma, as medidas de abertura construídas e descritas neste trabalho também apresentaram problemas de mensurabilidade ao refletir em seus índices a redução da taxa de câmbio brasileira durante a segunda metade da década de 1990. Assim, além da valorização cambial demonstrar sua influência sobre o quantum exportado e importado, a menor taxa de câmbio altera, artificialmente, os valores dos componentes dos coeficientes de abertura, tendendo a diminuí-los, principalmente em decorrência da superestimação de seus denominadores.

A média dos coeficientes de exportação industrial para os anos de 1991 a 1996, correspondendo ao período posterior à liberalização comercial, foi de 10,87\%. Quando realizado o mesmo cálculo para o período anterior à abertura, com o mesmo período amostral, compreenden-

${ }^{11}$ A média dos índices da taxa de câmbio real efetiva (IPA-DI com base fixa no ano de 1989, construída pela ponderação de 15 países) para os anos de 1995, 1996 e 1997 foi de, respectivamente, 80,$3 ; 82,8$ e 78,3. do os anos entre 1985 e 1990, o resultado foi de 10,95\%, ou seja, há uma estagnação dos coeficientes de abertura pelo lado das exportações. Fazendo o mesmo exercício para os coeficientes de importação, é obtido um resultado diferente, que aponta para o aumento do grau de abertura da economia. Tomando seis anos anteriores à liberalização comercial (1985 a 1990), é obtido o valor médio do coeficiente de importação de 6,17\%. Para os seis anos posteriores à liberalização (1991 a 1996), o valor médio foi de $8,77 \% .^{12}$

Os coeficientes agregados de abertura demonstraram comportamento semelhante ao observado nas medidas de abertura de Haguenauer, Markwald e Pourchet (1998). Houve queda dos coeficientes de exportação, mas, por outro lado, ocorreu crescimento nos coeficientes de importação. Os resultados obtidos nas três medidas alternativas de abertura, apesar dos problemas de mensuração, indicam uma ampliação dos fluxos comerciais brasileiros no que se refere às importações, sem, contudo, apresentar a elevação correspondente pelo lado das exportações, excetuando-se no que se refere às exportações provenientes do setor agropecuário.

A metodologia de construção dos coeficientes de abertura para o setor industrial e agropecuário mostrase tecnicamente mais vantajosa que aquelas empregadas para os coeficientes de Haguenauer, Markwald e Pourchet (1998), que é limitada ao setor industrial, e para os coeficientes agregados de abertura, que são demasiadamente amplos. A produção de um coeficiente menos genérico, mas que englobe os setores industrial e agropecuário produz uma medida mais acurada do inter-relacionamento comercial entre o Brasil e o resto do mundo. Os resultados do trabalho apontam nesse sentido, pois a mensuração dos coeficientes de importação e exportação realizada pelo coeficiente de abertura para o setor industrial e agropecuário parece ser aquela de maior aderência à realidade brasileira pós-liberalização comercial.

Observa-se ainda que menores taxas de câmbio irão reduzir tanto os coeficientes de importação quanto os coeficientes de exportação ${ }^{13}$. Em consequência, ambos os coeficientes deveriam apresentar tendência declinante. Verifica-se efetivamente que houve estagnação ou mes-

\footnotetext{
${ }^{12}$ Análise construída a partir dos dados dispostos em Haguenauer, Markwald e Pourchet (1998).

${ }^{13}$ Pela variação espúria nos denominadores.
} 
mo redução dos coeficientes de exportação, casos dos coeficientes de Haguenauer, Markwald e Pourchet (1998) e dos coeficientes agregados de abertura. Em contraposição, há um vigoroso crescimento dos coeficientes de importação. Dessa forma, evidencia-se que as variações ocorridas nos coeficientes de abertura também refletem a política comercial brasileira empreendida no início da década de noventa.

\section{Referências}

BONELLI, Regis. Abertura comercial e penetração das importações e exportações: notas e resultados preliminares. Rio de Janeiro: Paz e Terra, 1997.

BRUNO, Michael. High inflation and the nominal anchors of an open economy: Essays in International Finance n. 183. Princeton, New Jersey: Princeton Univesity, International Finance Section, 1991.

CALVO, Guillermo A.; VÉGH, Carlos A. Exchangerate based stabilisation under imperfect credibility. In: FRISCH, Helmut; WORGOTTER, Andreas. Openeconomy macroeconomics. Londres: MacMillan Press, 1993.

CALVO, Guillermo A.; VÉGH, Carlos A. Inflation stabilization and BOP crises in developing countries. In: TAYLOR, John; WOODFORD, Michael. Handbook of macroeconomics. Amsterdam: North Holland, 1998.

DOMBUSCH, Rudiger. Inflation, exchange rates, and stabilization. Essays in International Finance $n$. 165. Princeton, New Jersey: Princeton University, International Finance Section, 1986.

EDWARDS, Sebastian. Exchange-rate anchors, credibility, and inertia: a tale of two crises, Chile and Mexico. The American Economic Review, v. 86, p. 176-180, 1996.

FONSECA, Renato; CARVALHO JÚNIOR, Mário C. de; POURCHET, Henry. A orientação externa da indústria de transformação brasileira após a liberalização comercial. Revista de Economia Política, v. 20, p. 22-38, 2000.
HAGUENAUER, Lia; MARKWALD, Ricardo , A.; POURCHET, Henry. Estimativas do valor da produção industrial e elaboração de coeficientes de exportação e importação da indústria brasileira (1985-96): Texto para Discussão n 563. Brasília: IPEA, 1998.

MELO, Fabiana Xavier D. de. A taxa virtual: uma alternativa para a taxa de câmbio de equilíbrio. 1998. Dissertação (Mestrado em Economia) - Universidade de Brasília, Brasília, 1998.

MOREIRA, Maurício Mesquita; CORREA, Paulo G.. Abertura comercial e indústria: o que pode se esperar e o que se vem obtendo. Revista de Economia Política, v. 17, p. 61-91, 1997.

REBELO, Sergio; VÉGH, Carlos A. Real effects of exchange rate-based stabilization: an analysis of competing theories. In: BERNANKE, Bem S.; ROTEMBERG, Julio (Org.). NBER-Macroeconomics Annual. Massachusetts: MIT Press, 1995.

SOARES, Fernando Antônio R. A liberalização comercial e seus impactos alocativos na economia brasileira. 2000. Dissertação (Mestrado em Economia) - Universidade de Brasília, Brasília, 2000.

SOARES, Fernando Antônio R. Formação às fases da âncora cambial no Brasil: uma perspectiva histórica do Plano Real. Economia e Desenvolvimento, v. 9, p. 31-78, 2010.

SOARES, Fernando Antônio R.; PINTO, Maurício B. de Paula. Desequilíbrios cambiais e os fundamentos econômicos: uma análise do Plano Real. Revista de Economia Contemporânea, v. 12, p. 5-40, 2008.

SOARES, Fernando Antônio R.; NUNES, André. Liberalização comercial, déficit em transações correntes e âncora cambial no Brasil nos anos 90. Revista Universitas Relações Internacionais, Brasília, v. 8, p. 91-104, 2010. 


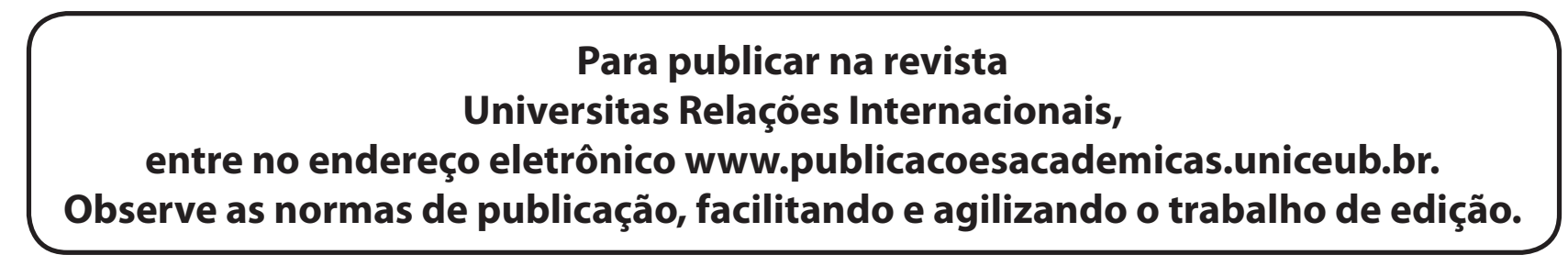

